\title{
Comment on: 'You've got dry macular degeneration, end of story: a qualitative study into the experience of living with non-neovascular age-related macular degeneration'
}

\author{
Jagdeep Singh Gandhi ${ }^{1}$
}

Received: 19 October 2019 / Accepted: 8 November 2019 / Published online: 13 December 2019

(c) The Royal College of Ophthalmologists 2019

\section{To the Editor:}

Taylor et al. have considered the care of patients with dry age-related macular degeneration (dAMD) [1]. British eye units are now so engulfed by the tides of wet AMD that the sufferers of dAMD can truly become second-class citizens.

Patients who have bilateral severe dAMD are prone to despair and some inevitably collapse into depression. In the rooms many specialists convey information with lucidity, but even so their words can be difficult to retain at the door. Doctors would do well to realise that some dAMD patients need long-lasting support. Practicality is paramount and clinics should customarily provide a handout of information.

One of our nurses has penned a booklet for patients that signposts towards the nearby institutes. National organisations for those with visual disability are also highlighted. These places have more time to counsel patients about distressing facets of AMD such as the Charles Bonnet syndrome. Equally helpful is a referral to a low-vision clinic for middling to marked dAMD. While being given magnifiers and lamps for near work, the referred persons are shown the trick of eccentric fixation.

From the viewpoint of lifestyle an enquiry should be made in regard to smoking. A strong link exists between tobacco and AMD. Lifelong smokers are classically untameable, but a few of the censured do desist from using tobacco. Smoked chemicals, for example, affect choroidal vessels [2], and can promote geographical atrophy at the macula. Besides smoking, patients are advised to ensure a normality of their blood pressure. Hypertension is a risk

Jagdeep Singh Gandhi

doctorjsg@gmail.com

1 Worcester Royal Eye Unit, Worcestershire Royal Hospital, Worcester WR5 1DD, United Kingdom factor for wet AMD. Owing to its sclerosing effect on vessels it may be relevant in the pathogenesis of dAMD. Macular protection can further be pursued via the taking of multivitamins, though smokers must take a concoction blended specially for them. This is because a mixing of tobacco and certain vitamins can brew up cancer [3].

Ophthalmologists should specifically confront the fear of blindness in AMD sufferers and delve into their home situations. In my area of rural England, for example, there are scores who subsist quietly on faded social support. Biomicroscopy of their eyes shows the pebbles of macular atrophy [4]. Registering the eligible as sight-impaired means the chore of filling forms, but it is a clerical step that opens up a continuum of support at the point of discharge. We ought not to overlook registration.

A finishing point is that the elderly with atrophic maculae often have a problematic grade of cataract. Operating on such opacity, I have seen how the resultant recovery of peripheral vision can boost mental wellbeing. Patients have less anxiety about locating an object or managing a flight of stairs. They desperately want personal autonomy. Thus those with endstage maculae are not irredeemable outcasts and surgeons should whittle down the extent of their visual disability.

\section{Compliance with ethical standards}

Conflict of interest The authors declare that they have no conflict of interest.

Publisher's note Springer Nature remains neutral with regard to jurisdictional claims in published maps and institutional affiliations.

\section{References}

1. Taylor DJ, Jones L, Binns AM, Crabb DP. 'You've got dry macular degeneration, end of story': a qualitative study into the experience 
of living with non-neovascular age-related macular degeneration. Eye. 2019. https://doi.org/10.1038/s41433-019-0445-8.

2. Wei X, Kumar S, Ding J, Khandelwal N, Agarwal M, Agrawal R. Choroidal structural changes in smokers measured using choroidal vascularity index. Investig Ophthalmol Vis Sci. 2019; 60:1316-20.
3. Evans JR. Antioxidant vitamin and mineral supplements for slowing the progression of age-related macular degeneration. Cochrane Database Syst Rev. 2006;7:CD000254.

4. Rees A, Zekite A, Bunce C, Patel PJ. How many people in England and Wales are registered partially sighted or blind because of agerelated macular degeneration? Eye. 2014;28:832-7. 